\title{
3 Research Square \\ Post-Transplant Diarrhea is Associated with Increased Rejection in Lung Transplant Recipients: A Retrospective Review
}

Aruj Choudhry ( $\sim$ achoudhry924@gmail.com )

Temple University Hospital

\section{Alexandera Selby}

Temple University Hospital

Padma Chamarthy

Temple University Hospital

Emily Friedman

Temple University Hospital

Navneet Goraya

Lewis Katz School of Medicine at Temple University

Andrew Leopold

Lewis Katz School of Medicine at Temple University

Michael Smith

Mount Sinai Health System

Ron Schey

University of Florida

Albert James Mamary

Temple University Hospital

Henry Parkman

Temple University Hospital

Kartik Shenoy

Temple University Hospital

Adam Ehrlich

Temple University Hospital

Zubair Malik

Temple University Hospital

Research article

Keywords: diarrhea, lung transplantation, Clostridiodes difficile, rejection 
Posted Date: October 6th, 2020

DOl: https://doi.org/10.21203/rs.3.rs-78199/v1

License: (c) (i) This work is licensed under a Creative Commons Attribution 4.0 International License. Read Full License 


\section{Abstract}

Background: Diarrhea causes significant morbidity among solid organ transplant recipients. It is well described in liver and kidney transplant recipients, yet data among lung transplant (LTX) recipients is lacking. The primary aim of this study was to characterize diarrhea in LTx recipients.

Methods: A retrospective review was performed for all patients undergoing LTx at our tertiary care hospital between 01/2011 and 02/2019. Patient demographics, type of LTX, and transplant indication were noted. Electronic medical records (EMR) were reviewed for the development of diarrhea (defined by clinical assessment and after obtaining diagnostic studies). Clostridiodes difficile infection (CDI) was determined by PCR testing. LTx rejection was determined by board-certified Pulmonologists as documented in the EMR.

Results: A total of 564 patients (66.3\% male, mean age $64.4 \pm 8.8$ years) underwent LTx during the 8-year study period, with 289 patients (51.2\%) experiencing post-LTx diarrhea. The most commonly identified etiologies of diarrhea were medication-induced (33.6\%) and CDI (15.6\%). Among patients with medication-induced diarrhea, mycophenolate mofetil (MMF) was the most common offending agent (33.3\%). Diarrhea and age were significantly associated with increased LTx rejection rates in multivariate analysis (Diarrhea OR=2.26, 95\% $\mathrm{Cl}=1.48-3.45$; $\mathrm{Age} \mathrm{OR=0.98,95 \%} \mathrm{Cl}=0.95-1.0$ ).

Conclusions: Diarrhea is common in LTx recipients, with medication-induced diarrhea being the most common etiology. Diarrhea and younger age were associated with an increased risk of LTx rejection. Recognizing the causes of diarrhea in LTx recipients is important for early diagnosis and treatment, leading to greater quality of life and improved graft function.

\section{Background}

Lung transplantation (LTX) is a well-established treatment strategy for patients with end-stage lung disease. While there have been improvements in surgical techniques, immunosuppressive regimens, and lung preservation strategies, it still remains a high-risk solid organ transplant [1]. Gastrointestinal (GI) complications are an important cause of postoperative morbidity as they can lead to drug malabsorption (including oral antirejection medications) and malnutrition. In kidney transplantation, diarrhea has been associated with an increased risk of graft failure and mortality [2]. Common causes of diarrhea in transplant recipients include infectious etiologies such as Clostridiodes difficile infection (CDI) and medications, including immunosuppressive agents. [3]

Complications due to diarrheal and colitis diagnoses are frequent but not well described among LTX recipients [4]. Diarrhea is defined as three or more loose or liquid stools per day. Evaluation of adults with diarrhea involves obtaining a history of duration and severity of symptoms, potential exposures (such as travel and food), recent antibiotic use, and a past medical history to determine whether the patient is immunosuppressed, could potentially have a nosocomial infection, or underlying inflammatory bowel disease. For high-risk patients, such as immunosuppressed organ transplant recipients, stool testing is 
performed to identify potential bacterial, viral, or parasitic pathogens that would inform treatment decisions and potential complications. For patients with a recent hospitalization, stool testing for CDI should be pursued, as it is the most common cause of hospital-acquired diarrhea $[5,6]$. Other important causes of acute diarrhea in the LTx population are viral etiologies, such as cytomegalovirus (CMV), graftversus-host disease (GVHD) and post-transplantation lymphoproliferative diseases (PTLD). Diagnosis in these patients involves general laboratory tests, such as a complete blood count, and endoscopic evaluation with biopsies. Furthermore, to determine the etiology of chronic diarrhea (diarrhea $>1$ month in duration), direct endoscopic evaluation of the colonic mucosa with a flexible sigmoidoscopy or colonoscopy may be warranted to obtain biopsies for microscopic evaluation $[3,5,6]$.

Diarrhea is common after LTx, though the incidence in the LTx population is unknown. Previous studies report a wide incidence ranging from $13-43 \%$ in other solid organ and bone marrow transplantation $[7,8]$. Furthermore, while distinct etiologies of diarrhea in liver and kidney transplant recipients are well documented, diarrhea in the LTx population remains poorly described, and there are few studies that have evaluated this complication. Nonetheless, anecdotal experience and available studies suggest that diarrhea is a significant cause of morbidity and discomfort among LTx recipients. Our retrospective cohort study had several aims:

- To describe the incidence and etiologies of post-LTx diarrhea at a high volume transplant institution.

- To describe the association between diarrhea and mortality.

- To describe the association between diarrhea and LTx rejection.

- To elucidate factors associated with an increased risk of CDI among LTx recipients.

- To describe the association between CDI and mortality.

- To describe the association between CDI and LTx rejection.

\section{Methods}

We retrospectively analyzed 564 patients who underwent either single or double LTx at Temple University Hospital between January 2011 and February 2019. Patient demographics, type of LTX, and indication for transplant were noted. LTx recipient charts were reviewed for the development of diarrhea in either the inpatient or outpatient setting. This study received IRB approval (IRB protocol 25631).

After obtaining a thorough history, stool studies (when deemed clinically appropriate), and therapeutic interventions, the etiology of the diarrhea was determined by the treating physician. For patients with negative tests and no clear inciting event for their diarrhea, their diarrheal episode was defined as diarrhea of unknown origin. All patients with diarrhea documented as an active medical problem were included. CDI was determined by confirmatory PCR testing. LTx rejection was determined by boardcertified Pulmonologists as documented in the EMR. Gastroenterology, infectious disease, and general surgery consultations were obtained as needed. 
Data were expressed as means and percentages. Odds ratios, confidence intervals, and probability values were calculated. Logistic regression and chi-square analyses were performed using SPSS v25.

\section{Results}

A total of 564 patients underwent either single or double LTx at our high volume LTx institution between January 2011 and February 2019 (mean age 64.4 \pm 8.8 years; 66.3\% male). Most LTx recipients (41.6\%) underwent bilateral sequential LTX, with the most common indication for LTx being restrictive/fibrotic lung disease (68.4\%). Of these 564 patients, 126 (22.3\%) had an episode of rejection, and $180(31.9 \%)$ were deceased at the time of the study.

Post-LTx diarrhea was noted in 289 of these patients (51.2\%; mean age $63.4 \pm 9.8$ years; $60.5 \%$ male). Late onset diarrhea (>30 days) (193 patients, [67.5\%]) was more common than early onset diarrhea (< 30 days) (92 patients [32.2\%]). At the time of the study, 99 patients (34.0\%) who developed post-LTx diarrhea were deceased as compared to 81 patients (29.8\%) who never developed post-LTx diarrhea (Table 1). 
Patient demographics of LTx recipients with diarrhea

Total Number of LTX

Recipients with Diarrhea
$\%$ of All LTx Recipients with Diarrhea

Gender

$\begin{array}{lll}\text { Male } & 176 & 60.5 \\ \text { Female } & 115 & 39.5\end{array}$

Age*

\begin{tabular}{lll}
$21-30$ years & 6 & 2.0 \\
\hline $31-40$ years & 5 & 1.5 \\
$41-50$ years & 11 & 3.8 \\
$51-60$ years & 58 & 19.8 \\
$61-70$ years & 147 & 50.3 \\
$71-80$ years & 64 & 21.9
\end{tabular}

Type of LTX

$\begin{array}{lll}R \text { Single } & 70 & 24.1 \\ \text { L Single } & 84 & 28.9 \\ \text { Bilateral Sequential } & 121 & 41.6 \\ \text { Double } & 16 & 5.5\end{array}$

Indication

for LTX

\begin{tabular}{lcc}
$\begin{array}{l}\text { Restrictive/Fibrotic } \\
\text { Lung Disease }\end{array}$ & 199 & 68.4 \\
$\begin{array}{l}\text { Obstructive Lung } \\
\text { Disease }\end{array}$ & 77 & 26.5 \\
$\begin{array}{l}\text { Pulmonary } \\
\text { Hypertension }\end{array}$ & 3 & 1.0 \\
\hline
\end{tabular}

* Mean Age of Onset: $64.4 \pm 8.8$ years.

** Idiopathic pulmonary fibrosis (IPF), Sarcoidosis, Combined pulmonary fibrosis and emphysema (CPFE), Acute respiratory distress syndrome (ARDS), Bronchiolitis obliterans organizing pneumonia (BOOP).

*** Chronic obstructive lung disease (COPD), Emphysema.

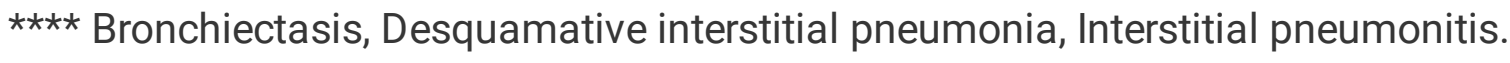


Total Number of LTX

Recipients with Diarrhea

Other****
$\%$ of All LTx Recipients with Diarrhea

2.7

Onset of

Diarrhea

$\begin{array}{lll}\text { Early Onset }(<30 \text { days }) & 92 & 32.2 \\ \text { Late Onset }(>30 \text { days }) & 193 & 67.5\end{array}$

Mortality

$\begin{array}{lcc}\text { Alive } & 192 & 66.0 \\ \text { Deceased } & 99 & 34.0\end{array}$

* Mean Age of Onset: $64.4 \pm 8.8$ years.

** Idiopathic pulmonary fibrosis (IPF), Sarcoidosis, Combined pulmonary fibrosis and emphysema (CPFE), Acute respiratory distress syndrome (ARDS), Bronchiolitis obliterans organizing pneumonia (BOOP).

$\star \star \star \star$ Chronic obstructive lung disease (COPD), Emphysema.

$\star \star \star \star$ Bronchiectasis, Desquamative interstitial pneumonia, Interstitial pneumonitis.

In both unadjusted and multivariate analyses, diarrhea was not associated with increased mortality among LTx recipients (univariate: $\mathrm{p}=0.28, \mathrm{OR}=1.22, \mathrm{Cl}=0.86-1.74$; multivariate, after controlling for age, gender, and LTx indication: $p=0.34, O R=1.19, \mathrm{Cl}=0.83-1.71$ ). Furthermore, the onset of diarrhea (early vs. late) was not associated with increased mortality (univariate: $p=0.16, O R=1.48, C l=0.86-2.54$; multivariate: $\mathrm{p}=0.17, \mathrm{OR}=0.68, \mathrm{Cl}=0.39-1.18)$ (Table 2$)$.

Table 2

Univariate and multivariate analysis for predictors of mortality in LTx recipients

\begin{tabular}{|lllll|}
\hline & $\begin{array}{l}\text { Odds Ratio } \\
\text { (OR) }\end{array}$ & $\begin{array}{l}\text { Univariate p- } \\
\text { value }\end{array}$ & $\begin{array}{l}\text { Adjusted } \\
\text { OR }\end{array}$ & $\begin{array}{l}\text { Multivariate p- } \\
\text { value }\end{array}$ \\
\hline $\begin{array}{l}\text { Early onset vs late onset } \\
\text { diarrhea }\end{array}$ & 1.48 & 0.16 & 0.68 & 0.17 \\
\hline Age & - & - & 1.0 & 0.72 \\
\hline Gender & - & - & 0.93 & 0.78 \\
\hline LTx indications* & - & - & & All $p>0.05^{\star}$ \\
\hline $\begin{array}{l}\text { *All LTx indications were controlled for in analysis: obstructive lung disease, fibrotic/restrictive lung } \\
\text { disease, pulmonary hypertension, and other. }\end{array}$ \\
\hline
\end{tabular}


Among all LTx recipients with diarrhea, 79 (27.2\%) developed acute, chronic, or combined (acute and chronic) rejection. Acute rejection was most common, occurring in 43 patients (14.8\%), with cellular rejection being the most common form of rejection in this cohort (13.1\%). (Table 3).

Table 3

LTx rejection in LTx recipients with diarrhea

\begin{tabular}{|lll|}
\hline Type of Rejection & $\begin{array}{l}\text { Total Number of LTx Recipients with } \\
\text { Evidence of Rejection }\end{array}$ & $\begin{array}{l}\text { Frequency among All LTx Recipients } \\
\text { with Diarmea (\%) }\end{array}$ \\
\hline Acute Rejection & 43 & 14.8 \\
\hline Chronic Rejection & 23 & 7.9 \\
\hline $\begin{array}{l}\text { Combined } \\
\begin{array}{l}\text { Acute and Chronic } \\
\text { Rejection) }\end{array}\end{array}$ & 13 & 4.5 \\
\hline Total & 79 & \\
\hline $\begin{array}{l}\text { Antibody Mediated } \\
\text { Rejection }\end{array}$ & 16 & 27.2 \\
\hline Cellular Rejection & 38 & 5.5 \\
\hline Not noted & 25 & 13.1 \\
\hline Total & 79 & 8.7 \\
\hline
\end{tabular}

In unadjusted and multivariate analyses, diarrhea was associated with increased rates of LTx rejection (univariate: $\mathrm{p}<0.001, \mathrm{OR}=2.22, \mathrm{Cl}=1.47-3.37$; multivariate: $\mathrm{p}<0.001, \mathrm{OR}=2.26, \mathrm{Cl}=1.48-3.45$ ). In addition, multivariate analysis demonstrated that younger age was associated with increased rates of LTx rejection $(p=0.04, \mathrm{Cl} 0.98, \mathrm{Cl}=0.95-1.0)$ (Table 4).

Table 4

Logistic regression for predictors of rejection in LTx recipients

\begin{tabular}{|llll|}
\hline & \multicolumn{1}{c}{ Adjusted OR } & $95 \% \mathrm{Cl}$ & P-value \\
\hline Diarrhea & 2.26 & $1.48-3.45$ & $<0.01$ \\
\hline Age & 0.98 & $0.95-1.0$ & 0.04 \\
\hline Gender & 0.93 & $0.61-1.43$ & 0.75 \\
\hline LTx Indications* & & All $p>0.05$ \\
\hline $\begin{array}{l}\text { *All LTx indications were controlled for in analysis: obstructive lung disease, fibrotic/restrictive lung } \\
\text { disease, pulmonary hypertension, and other. }\end{array}$ & \\
\hline
\end{tabular}

The most commonly identified etiologies of diarrhea in LTx recipients were medication-induced diarrhea (97 patients [33.6\%]) and CDI (45 patients [15.6\%]). There were a considerable number of patients with 
diarrhea of unknown origin (89 patients [30.8\%]). Other less common etiologies were diet or enteral nutrition, viral etiologies (including cytomegalovirus), and chronic diarrheal syndromes such as irritable bowel syndrome (IBS) (Table 5).

Table 5

Etiologies of diarrhea in LTx recipients

\begin{tabular}{|lll|}
\hline Etiology of Diarrhea & $\begin{array}{l}\text { Total Number of LTx Recipients with } \\
\text { Diarrhea }\end{array}$ & $\begin{array}{l}\text { \% of All LTx Recipients with } \\
\text { Diarrhea }\end{array}$ \\
\hline Medication-Induced & 97 & 33.6 \\
\hline CDI & 45 & 15.6 \\
\hline Diet and Tube Feeds & 15 & 5.2 \\
\hline Other* & 15 & 5.2 \\
\hline Viral (incl. CMV) & 14 & 4.8 \\
\hline Chronic (incl. IBS) & 14 & 4.8 \\
\hline $\begin{array}{l}\text { Diarrhea of Unknown } \\
\text { Origin }\end{array}$ & 89 & 30.8 \\
\hline $\begin{array}{l}\text { *Post-infectious GI Dysmotility Syndrome, small bowel obstruction, chronic pancreatitis, diverticulitis, } \\
\text { dumping syndrome, rectal cancer/chemotherapy/radiation. }\end{array}$ \\
\hline
\end{tabular}

Among patients with medication-induced diarrhea (mean age $65.2 \pm 7.5$ years; $58.5 \%$ male), mycophenolate mofetil (MMF) was the most common etiology (33.3\%; mean age $64.9 \pm 10.0$ years; $48.4 \%$ male), followed by tacrolimus/sirolimus ( $7.5 \%$; mean age $66.9 \pm 5.7$ years; $57.1 \%$ male), atovaquone ( $7.5 \%$; mean age $66.7 \pm 7.3$ years; $57.1 \%$ male), and magnesium ( $7.5 \%$; mean age $64.0 \pm 4.5$ years; $71.4 \%$ male). Lactulose, nintedanib, and metformin resulted in early onset diarrhea $(14.3,24.0$, and 26.3 days after LTx respectively) while the remaining medications noted in Table 6 largely resulted in lateonset diarrhea. 
Table 6

Medication-induced diarrhea in LTx recipients

\begin{tabular}{|c|c|c|c|c|c|}
\hline Medication & $\begin{array}{l}\text { Total Number of LTx } \\
\text { Recipients with } \\
\text { Medication-Induced } \\
\text { Diarrhea }\end{array}$ & $\begin{array}{l}\text { \% of } \\
\text { Medication- } \\
\text { Induced } \\
\text { Diarrhea }\end{array}$ & $\begin{array}{l}\text { Mean } \\
\text { Age } \\
\text { (Years) }\end{array}$ & $\begin{array}{l}\text { Gender } \\
\text { (\% } \\
\text { Male) }\end{array}$ & $\begin{array}{l}\text { Onset of } \\
\text { Diarrhea } \\
\text { After LTx } \\
\text { (Days) }\end{array}$ \\
\hline $\begin{array}{l}\text { Mycophenolate } \\
\text { Mofetil }\end{array}$ & 31 & 33.3 & 64.9 & 48.4 & 267.6 \\
\hline Tacrolimus/Sirolimus & 7 & 7.5 & 66.9 & 57.1 & 476.3 \\
\hline Atovaquone & 7 & 7.5 & 66.7 & 57.1 & 172.7 \\
\hline Magnesium & 7 & 7.5 & 64.0 & 71.4 & 510.3 \\
\hline Stool Softeners & 6 & 6.5 & 66.3 & 50.0 & 126.3 \\
\hline $\begin{array}{l}\text { Immunosuppression } \\
\text { NOS }\end{array}$ & 4 & 4.3 & 61.8 & 50.0 & 397.0 \\
\hline Lactulose & 3 & 3.2 & 62.3 & 66.7 & 14.3 \\
\hline Metformin & 3 & 3.2 & 68.3 & 100 & 26.3 \\
\hline Nintedanib & 1 & 1.1 & 69.0 & 0.0 & 24.0 \\
\hline Other* & 11 & 11.8 & 65.6 & 90.9 & 190.4 \\
\hline Not Noted & 13 & 14.0 & 64.5 & 46.2 & 426.3 \\
\hline
\end{tabular}

CDI occurred in 45 patients (mean age $61.6 \pm 9.9$ years; $66.7 \%$ male) and was further subdivided into early $\mathrm{CDI}$ (<30 days) and late CDI (>30 days). Early CDI occurred in 15 patients (mean age $60.3 \pm 12.0$ years; $80 \%$ male) with a mean onset of $17.1 \pm 6.7$ days post-LTx. Late CDI developed in 30 patients (mean age $61.8 \pm 8.7$ years; $60 \%$ male) with a mean onset of $400.5 \pm 401.4$ days post-LTx (Table 7). The presence of rejection increased the likelihood of $\mathrm{CDI}(\mathrm{OR}=2.65, \mathrm{p}=0.003,95 \% \mathrm{Cl} 1.39-5.06)$. However, other LTx recipient factors were not significant predictors for $\mathrm{CDI}$ development (Table 8). At the time of this study, 19 patients $(42.2 \%)$ with CDI were deceased. CDI did not increase the risk of mortality in LTX recipients $(p=0.16)$. Furthermore, timing of $C D I$ (early vs. late) was not associated with an increased risk of mortality $(p=0.39)$. There were no reported deaths secondary to CDI. 
Table 7

Early vs late CDI in LTx recipients

\begin{tabular}{|lllllll|}
\hline & $\begin{array}{l}\text { Total Number of } \\
\text { LTx Recipients } \\
\text { with CDI }\end{array}$ & $\begin{array}{l}\text { \% of All } \\
\text { LTx } \\
\text { Recipients }\end{array}$ & $\begin{array}{l}\text { Mean } \\
\text { Age } \\
\text { (Years) }\end{array}$ & $\begin{array}{l}\text { Gender } \\
\text { (\% } \\
\text { Male) }\end{array}$ & $\begin{array}{l}\text { Onset of } \\
\text { Diarrhea } \\
\text { After LTx } \\
\text { (Days) }\end{array}$ & $\begin{array}{l}\text { Number of Deceased } \\
\text { LTx Recipients with CDI } \\
\text { at Time of Study }\end{array}$ \\
\hline $\begin{array}{l}\text { Early } \\
\text { CDI }\end{array}$ & 15 & 2.7 & 60.3 & 80.0 & 17.1 & 5 \\
\hline $\begin{array}{l}\text { Late } \\
\text { CDI }\end{array}$ & 30 & 5.3 & 61.8 & 60.0 & 400.5 & 14 \\
\hline $\begin{array}{l}\text { CDI } \\
\text { (Total) }\end{array}$ & 45 & 8.0 & 61.6 & 66.7 & 288.3 & 19 \\
\hline
\end{tabular}

Table 8

Logistic regression for predictors of CDI in LTx recipients

\begin{tabular}{|llll|}
\hline & Adjusted OR & $95 \% \mathrm{Cl}$ & P-value \\
\hline Age & 0.99 & $0.96-1.0$ & 0.50 \\
\hline Gender & 1.19 & $0.60-2.32$ & 0.62 \\
\hline Rejection & 2.65 & $1.39-5.06$ & 0.003 \\
\hline LTx Indications* & & All $p>0.05$ \\
\hline $\begin{array}{l}\text { *All LTx indications were controlled for in analysis: obstructive lung disease, fibrotic/restrictive lung } \\
\text { disease, pulmonary hypertension, and other. }\end{array}$ & \\
\hline
\end{tabular}

\section{Discussion}

Diarrhea is a frequently encounter encountered symptom in LTx recipients, occurring in $51.2 \%$ of our cohort. Diarrhea is of particular clinical significance, as it may lead to other serious adverse effects such as graft rejection (possibly from inadequate absorption of antirejection medications), dehydration, malabsorption, and medication non-adherence. In our study, we found that the most frequent cause of diarrhea in LTx recipients was medication-induced diarrhea (97 patients [33.6\%]) followed by diarrhea due to CDI (45 patients [15.6\%]). These findings correlate with previous studies and our anecdotal experience with LTx recipients: medication-associated side effects and infection are common causes for diarrhea [3, 9]. It can be postulated that the use of immunosuppressive agents and broad-spectrum antibiotics in the immediate post-operative period account for these findings.

Studies among kidney transplant recipients demonstrate that post-transplant diarrhea varies by immunosuppressive regimen, ranging from 9-33\% [10]. LTx recipients at our institution are most commonly started on MMF, tacrolimus, and low dose prednisone. MMF has been frequently implicated in post-transplant diarrhea. In a meta-analysis by Knight et. al, a significant increase in the risk of diarrhea 
was observed with MMF (RR 1.57, $\mathrm{Cl} 1.33-1.86, \mathrm{p}<0.0001)$ [9]. Our results are consistent with this finding, as MMF use was shown to be the most common cause of medication-induced diarrhea in our cohort. It is proposed that MMF can cause direct drug toxicity and damage by inhibiting replication and repair of intestinal epithelial cells, thus leading to diarrhea [11].

Tacrolimus is also associated with an increased risk of diarrhea. Studies have shown that the incidence of post-transplant diarrhea due to tacrolimus is increased in liver and kidney transplant recipients. Ginsbrug et. al reviewed diarrhea in liver transplant recipients and described the LIS2T trial (Levy et. al), which compared the microemulsion form of cyclosporine with tacrolimus. Notably, the incidence of diarrhea was significantly higher in the tacrolimus group ( $29 \%$ vs. $14 \%, p<0.001)$ compared to cyclosporine. This association was further described in the Symphony study by Ekberg et, al, in which several immunosuppressant agents in renal transplant recipients were evaluated for adverse events. The tacrolimus group was noted to have the highest incidence of diarrhea $(27.4 \%)[10,12]$. The mechanism of diarrhea in patients receiving calcineurin inhibitors is unknown. However, when evaluating kidney transplant patients, the tacrolimus trough levels were significantly elevated before the onset of diarrheal symptoms [12]. This suggests that tacrolimus itself is toxic to the GI epithelium, thereby leading to diarrhea. Furthermore, tacrolimus may have an effect on intestinal motilin receptors to some degree given its' macrolide structure [13].

CDI was noted to be the second most common cause of diarrhea in our cohort. The incidence and clinical course are influenced by a variety of factors: patient co-morbidities, concurrent illnesses, and the degree and duration of broad-spectrum antimicrobial exposure [12].

CDI is associated with increased mortality in solid organ transplants, although data is scarce in LTx recipients. Lee et. al performed a retrospective record review of 388 patients which showed that LTX recipients who developed CDI (89 patients [22.9\%]) had a higher risk of death, especially when CDI developed within the first 6 months of LTx [14]. Notably, our large cohort study did not show that the development of CDI (45 patients [15.6\%]) was associated with an increased risk of mortality in either early or late CDI. Since 2011, our institution has implemented a CDI treatment protocol in all patients with a history of CDI. These patients preemptively received oral vancomycin $125 \mathrm{mg}, 4$ times daily while on antibiotics and for 7 days thereafter. While this was not the focus of the study nor directly evaluated, this could account for the lower incidence of $\mathrm{CDI}$ and therefore, no significant association with mortality observed in our cohort.

Importantly, CDI development was significantly associated with presence of rejection $(O R=2.65, p=$ 0.003). It is plausible this observation is due to broad-spectrum antibiotics, especially in the setting of a decompensated patient presentation (e.g. a hypoxic LTx patient presenting with infiltrates on chest imaging and ultimately found to be in rejection). LTx recipients receive aggressive antimicrobial and immunosuppressive therapy postoperatively, thereby making them susceptible to infection. The initial broad-spectrum antibiotic use along with immune suppression could lead to heightened risk of CDI development in LTx recipients. 
It is interesting to note that among LTx recipients who developed late onset CDI, the mean onset was 400.5 days post-LTX, suggesting that providers must remain vigilant of diarrhea that develops $>1$ year after LTX and continue to screen for CDI when deemed clinically appropriate. CDI constitutes a significant proportion of post-LTx diarrhea and therefore requires efforts to control transmission of disease and prompt recognition to facilitate management.

Our study demonstrates that diarrhea is associated with an increased risk for LTx rejection. This can be due to a number of factors. Diarrhea may reduce absorption of anti-rejection medications, either by leading to rapid transit of medications through the GI tract or by direct injury to the small bowel, thereby leading to increased rejection. If frequent dose adjustments are required to alleviate diarrheal symptoms, this may lead to sub-therapeutic immunosuppression levels. Lastly, discontinuation of immunosuppressive medications with trials of other immunosuppressive medications by either patients or clinicians can result in graft dysfunction and rejection. Of note, younger LTx recipients were at increased risk for LTx rejection when compared with their older counterparts. This finding is in keeping with current literature that suggests that increased age is associated with decreased rejection rates. Vadnerkar et. al performed a retrospective review of LTx recipients at their institution. The authors noted that LTx rejection was more common among patients 60-65 years old as compared to those $>65$ years old, hypothesizing that age-associated immunosenescence may be responsible for lower rejection rates among older LTx recipients [15].

Lastly, recipient factors (i.e. age, gender, and indication for transplant) did not influence the development of post-LTx diarrhea in our study, suggesting that post-LTx diarrhea is an independent complication that can be seen in any patient, making post-operative vigilance and preemptive measures important for all post-LTx patients.

This is a large, single-center study evaluating LTx recipients and a common, yet poorly described postoperative complication: diarrhea. Temple University Hospital is a major lung transplant center, allowing for significant data collection and observation. Limitations of our study include bias inherent to retrospective studies. Variations in diagnostic workups and interventions during the study period may lend to variable patterns and duration of symptoms. Many of our patients travel from far distances for LTx evaluation and thus may have completed GI evaluations outside our institution, leading to additional variation, as some data may not have been captured. Our study could be strengthened by the addition of information on all stool and endoscopic testing done outside our institution, antibiotic duration, diarrheal complications leading to surgical intervention, and the hospitalization rate due to diarrheal symptoms. In addition, not all providers documented the proposed etiology of diarrhea, which further limits analysis.

Our study was performed prior to the onset of the severe acute respiratory syndrome coronavirus 2 (SARS-CoV-2) pandemic. While patients with SARS-CoV-2 often present with respiratory symptoms and fever, GI symptoms have been reported, including diarrhea in up to $50 \%$ of patients [16]. In a multi-center study conducted in China, Pan et. al investigated patients presenting with digestive symptoms (103 patients) and found that anorexia (81 patients [78.8\%]) and diarrhea (35 patients [34\%]) were most 
commonly reported. At present, little is known about the relationship between SARS-CoV-2 and post-LTx diarrhea but should be explored in future analyses [17].

\section{Conclusions}

As seen in other solid organ transplant populations, post-LTx diarrhea is a frequently encountered phenomenon. Our large retrospective review identifies diarrhea occurring in more than half of all LTX recipients, with medication-induced diarrhea representing the most substantial etiology, followed by CDI. Importantly, diarrhea is significantly associated with increased LTx rejection. Perhaps diarrhea interferes with the antirejection therapies, limiting contact time for absorption. It is also reasonable to speculate that these medications are being discontinued due to the diarrheal side effects, leading to rejection. Recognizing the etiologies of diarrhea in LTx recipients and their prevalence allows for early diagnosis and expedient delivery of appropriate medical management, which is of the uptmost importance for improving quality of life and preventing graft rejection.

\section{Abbreviations}

CDI: Clostridiodes difficile infection

CMV: cytomegalovirus

EMR: electronic medical records

Gl: gastrointestinal

GVHD: graft-versus-host disease

LTx: lung transplantation

MMF: mycophenolate mofetil

PTLD: post-transplantation lymphoproliferative diseases

\section{Declarations}

\section{Ethical approval and consent to participate:}

All procedures performed in studies involving human participants were in accordance with the ethical standards of the institutional and/or national research committee and with the 1964 Helsinki declaration and its later amendments or comparable ethical standards. For this retrospective study, formal consent is not required. The study design was reviewed and approved by our Institutional Review Board (IRB) and the need for written informed consent was waived. This article does not contain any studies with animals performed by any of the authors. 


\section{Consent for publication:}

Not applicable.

\section{Availability of data and materials:}

The dataset used and/or analyzed during this current study are available from the corresponding author on reasonable request.

\section{Competing interests:}

The authors declare that they have no competing interests.

\section{Funding:}

None

\section{Authors's contributions:}

AC collected and analyzed data, did literature review, and wrote the manuscript.

AS collected and analyzed data, did literature review, and helped with manuscript preparation.

PC helped with data collection and reviewed the manuscript.

EF helped with data collection and reviewed the manuscript.

NG helped with data collection and reviewed the manuscript.

AL helped with data collection and reviewed the manuscript.

JG helped with abstract preparation and reviewed the manuscript.

MS helped with manuscript revision and data analysis.

RS helped with manuscript revision.

AJM evaluated patients included in the study and helped with manuscript preparation.

HPP helped with data analysis and critical revision of the manuscript.

KS evaluated patients included in the study and helped with manuscript preparation.

AE helped with manuscript preparation, critical revision, and data analysis.

ZM planned and supervised the study, evaluated patients included in the study, analyzed data, did literature review and critical revision of the manuscript. 
All authors approve the final version of the manuscript.

\section{Acknowledgement of Grant Support/Disclosure of Financial Arrangements:}

None

\section{Disclosures:}

An abstract of this study was accepted for presentation at Digestive Disease Week (DDW) 2020 and published in Gastroenterology.

\section{References}

1. Yusen RD, Edwards LB, Kucheryavaya AY, et al. The Registry of the International Society for Heart and Lung Transplantation: thirty-second official adult lung and heart-lung transplantation report2015; focus theme: early graft failure. [I] J Heart Lung Transpl [1]. 2015; 34:1264-77.

2. Shad S, Hanif F, Haq MU, et al. Frequencies of Common Infectious Organisms Causing Chronic Diarrhea in Renal Transplant Patients. [1] Experimental and Clinical Transplantation 2019 [1]. 17(Suppl 1): 212-215.

3. Ginsburg PM, Thuluvath PJ. Diarrhea in liver transplant recipients: Etiology and management. [1] Liver Transplantation [1]. 2005; 11: 881-890.

4. Paul S, Escareno CE, Clancy K, et al. Gastrointestinal Complications After Lung Transplantation. [1] The Journal of Heart and Lung Transplantation [1]. 2009; 28;5: 475-479.

5. Riddle MS, DuPont HL, Connor BA. ACG Clinical Guideline: Diagnosis, Treatment, and Prevention of Acute Diarrheal Infections in Adults. [I]The American Journal of Gastroenterology [I]. 2016; 111: 602622.

6. Shane AL, Mody RK, Crump JA, et al. 2017 Infectious Diseases Society of America Clinical Practice Guidelines for the Diagnosis and Management of Infectious Diarrhea. [I]Clin Infect Dis [I]. 2017; 65: e45-e80.

7. Cox GJ, Matsui SM, Lo RS, et al. Etiology and outcome of diarrhea after marrow transplantation: A prospective study. [1] Gastroenterology[I]. 1994;107:1398-1407.

8. Altiparmak MR, Trablus S, Pamuk ON, et al. Diarrhoea following renal transplantation. [1] Clinical Transplantation [I]. 2002;16:212-216.

9. Knight SR, Russell NK, Barcena L, et al. Mycophenolate Mofetil Decreases Acute Rejection and may Improve Graft Survival in Renal Transplant Recipients When Compared with Azathioprine: A Systematic Review. [I] Transplantation [1]. 2009;87: 785-794.

10. Ekberg H, Tedesco-Silva H, Demirbas A, et al. Reduced Exposure to Calcineurin Inhibitors in Renal Transplantation. [1] New England Journal of Medicine [1]. 2007;357: 2562-2575.

11. Aulagnon F, Scemla A, Dewolf S, Legendre C, Zuber J. Diarrhea After Kidney Transplantation. [I] Transplantation [1]. 2014;98: 806-816. 
12. Ekberg H, Bernasconi $\mathrm{C}$, Noldeke J, et al. Cyclosporine, tacrolimus and sirolimus retain their distinct toxicity profiles despite low doses in the Symphony study. [1] Nephrology Dialysis Transplantation [I]. 2010;25: 2004-2010.

13. Dall'Agnol DJR, Corá LA, Teixeira M do CB, et al. Gastrointestinal disorders after immunosuppression: an experimental model to evaluate the influence of monotherapy on motility parameters. [1] Experimental Physiology [1]. 2017;102: 924-933.

14. Lee J, Kelly R, Hertz M,et al. Clostridium Difficile Infection Increases Mortality Risk in Lung Transplant Recipients. [1] The Journal of Heart and Lung Transplantation [1]. 2013;32: S48-S49.

15. Vadnerkar A, Toyoda $Y$, Crespo $M$, et al. Age-specific complications among lung transplant recipients 60 years and older. [1] The Journal of Heart and Lung Transplantation [1]. 2011;30: 273-281.

16. D'Amico F, Baumgart DC, Danese S, et al. Diarrhea during COVID-19 infection: pathogenesis, epidemiology, prevention and management. [I] Clinical Gastroenterology and Hepatology [I]. 2020;0(0).

17. Pan L, Mu M, Yang P, et al. Clinical Characteristics of COVID-19 Patients With Digestive Symptoms in Hubei, China: A Descriptive, Cross-Sectional, Multicenter Study. [1] Am J Gastroenterol [1]. 2020;115: 766-773. 